\title{
PERFIL DO MERCADO VAREJISTA E CONSUMIDOR DE MAMÃO DOS GRUPOS 'SOLO' E 'FORMOSA' DO DISTRITO FEDERAL -DF'
}

\author{
SANDRO BEVILAQUA RANGEL², GENI RODRIGUES FAGUNDES ${ }^{3}$, THALES CABRAL CIRQUEIRA FALCÃO4, \\ RICARDO DE SOUSA MENDES ${ }^{4}$, OSVALDO KIYOSHI YAMANISHI
}

\begin{abstract}
RESUMO - Este estudo analisou os principais fatores envolvidos na comercialização do mamão em 27 supermercados e 27 varejões do Distrito Federal (Brasília e cidades satélites), no período de janeiro a dezembro de 2001. Entrevistaram-se 162 consumidores. Na tabulação e análise dos questionários, obteve-se: o principal fornecedor de mamão para o varejo foi a Ceasa-DF; a presença de danos físicos foi o principal aspecto observado pelos responsáveis pela compra; os frutos são expostos em prateleiras sem refrigeração, e o responsável pelo prejuízo ocasionado pelas perdas foi o próprio estabelecimento varejista. Os estabelecimentos varejistas diferenciaram-se em alguns tópicos, tais como: responsável pela compra, existência de contrato; forma de exposição dos frutos; grau de maturação dos frutos adquiridos, e acompanhamento das perdas. Os consumidores preferem frutos nos estádios 3 a 5 (acima de $25 \%$ da superfície amarela); escolhem o estabelecimento para compra de mamão orientados pela qualidade e preço; não pagariam mais por um mamão embalado e classificado, preferindo mamão a granel pela possibilidade de escolher-se o fruto que mais lhe agrade no momento da compra, e elegeram, como principal problema, a presença de frutos com danos físicos.
\end{abstract}

Termos para indexação: comercialização, mamão, varejo, consumidor, qualidade.

\section{PROFILE OF RETAIL MARKET AND CONSUMERS OF PAPAYA FROM'SOLO' AND 'FORMOSA' GROUP IN FEDERAL DISTRICT-DF}

\begin{abstract}
The main factors involved in the commercialization of papaya in 27 supermarkets and 27 retail shops of Federal District (Brasília and satellite cities) was studied from January to December of 2001. The data was colleted using questionnaire answered by the manager of the establishment and by 162 consumers. It was observed that the wholesalers of Federal District Wholesale Market (CEASA-DF) was the main supplier of papaya to the retail market; physical damage was the main aspect to be observed by those responsible for the purchase; papaya fruits for selling were displayed in unrefrigerated racks; the retail markets themselves bore the financial losses. The retail market differed in relation of: who purchase the papaya fruits; contracts with the wholesaler; how to expose the fruit; maturation of purchased fruits; and follow-up of losses. It was found that consumers preferred: fruits in the $3^{\text {rd }}$ to $5^{\text {th }}$ stage of maturation; to choose papaya retail market they based on quality and price; not to pay more for wrapping and classification, opting for unwrapped fruit in order to choose the preferred fruit. Consumers reported physical damage to be the primary inhibitor to purchase.
\end{abstract}

Index terms: commercialization, papaya, retail market, consumers, quality.

\section{INTRODUÇÃO}

Com o surgimento de novos canais de venda, vem alterandose o perfil da comercialização de frutas, com a comercialização sendo descentralizada, pequeno decréscimo da participação dos grandes entrepostos e de centros de abastecimento e crescente negociação direta dos produtores junto aos varejões e supermercados.

Em razão da maior exigência dos consumidores, o mercado varejista passou a investir mais na estrutura de comercialização por meio de medidas como: treinamento para capacitar funcionários; melhoria na forma de exposição dos frutos; ofertas promocionais em certos dias da semana; abertura de canais para reclamações, e sugestões no próprio estabelecimento. Os novos canais de comercialização são mais exigentes em qualidade e não dispõem de infra-estrutura para trabalhar com as embalagens tradicionais - madeira (Fipe, 1999). No entanto, esses novos canais são os que pagam, em geral, o menor preço aos fornecedores.

Hoje, o consumidor é bem diferente do consumidor do passado, pois tem acesso a grande diversidade de informações sobre o produto que irá comprar, exigindo um atendimento melhor e diferenciado (Gonçalves, 2001). Diversos aspectos influenciam o hábito dos consumidores como: faixa etária; renda familiar; maior grau de informação; aumento da preocupação com a saúde; maior atuação da mulher no mercado de trabalho, e aumento das refeições feitas fora de casa (Amaro, 1998).

No Brasil, estudos sobre cadeias produtivas de frutas não determinam, adequadamente, os perfis dos varejistas nem do consumidor final (Amaro, 1997). Portanto, é fundamental que seja realizado um estudo visando a conhecer melhor o perfil de ambos para que haja uma melhoria na estrutura de comercialização.

O trabalho objetivou analisar o perfil dos mercados varejista e do consumidor de mamão do Distrito Federal, com a finalidade de fornecer informações que poderão ser utilizadas pelo mercado varejista para traçar metas, estratégias e ações táticas.

\section{MATERIAL E MÉTODOS}

O trabalho foi realizado em Brasília, de janeiro a dezembro de 2001, baseando-se na coleta de dados por meio da aplicação de questionários específicos para os mercados varejista e consumidor. Utilizouse, como fonte de referência para a determinação do plano amostral e elaboração dos questionários, a pesquisa realizada pela Intelecto Consultoria, Estudos e Projetos (1998).

Selecionaram-se, aleatoriamente, 54 estabelecimentos varejistas, sendo 27 supermercados e 27 varejões distribuídos nas regiões administrativas do Distrito Federal (DF), da seguinte forma: 16 estabelecimentos em Brasília+ (Brasília, Paranoá, Cruzeiro, São Sebastião, Lago Sul, Lago Norte e Candangolândia), 8 estabelecimentos na Ceilândia, 8 em Taguatinga, 6 no Gama+ (Gama, Santa Maria e Recanto das Emas), 4 em Samambaia, 4 em Planaltina, 4 em Sobradinho e 2 no Núcleo Bandeirante+ (Núcleo Bandeirante e Riacho Fundo). Em cada mercado varejista, foram entrevistados 3 clientes, maiores de idade, que se encontravam

\footnotetext{
1 (Trabalho 110/2002). Recebido: 25/07/2002; Aceito para publicação: 20/03/2003. Parte da tese do primeiro autor apresentada à Universidade de Brasília, para a obtenção do grau de "Magister Scientiae".

${ }^{2}$ Eng. Agr. Msc. Bolsista DTI/CNPq do Setor de Fruticultura da Estação Experimental da Biologia (EEB) da Universidade de Brasília (UnB). Tel. (61) 307-2997. Email: sbrangel@brturbo.com

${ }^{3}$ Eng. Agr. MSc. Bolsista DTI/CNPq do Setor de Fruticultura da EEB/UnB. Tel. (61) 307-2997.E-mail: genifagundes@bol.com.br

${ }^{4}$ Graduandos do curso de Agronomia-UnB. E-mail: thalesfalcao@bol.com.br; ricardounb@bol.com.br.

${ }^{5}$ Eng. Agr. PhD, Professor Adjunto III da Faculdade de Agronomia e Medicina Veterinária da UnB. Bolsista de Pesquisa 2C do CNPq. Campus Darcy Ribeiro, Cx. P. 04508, CEP 70.910-970, Brasília-DF. Tel. (61) 307-3247. E-mail: kiyoshi@unb.br
} 
no setor de hortifruti. A definição do número de clientes por loja foi arbitrária e buscou alcançar critérios de comparabilidade com pesquisas semelhantes realizadas em outros Estados. Tentou-se não repetir, dentro do possível, o sexo dos consumidores; se o primeiro fosse um homem, o seguinte deveria ser uma mulher e assim por diante. Utilizou-se questionário voltado aos gerentes e dirigentes dos locais de vendas (mercado varejista). Os estádios de maturação foram divididos em: estádio 0 - fruto $100 \%$ verde; estádio 1 - até $15 \%$ da superfície amarela; estádio $2-16$ a $24 \%$ da superfície amarela, estádio $3-25$ a $50 \%$ da superfície amarela; estádio $4-51 \%$ a $75 \%$ da superfície amarela; e estádio 5 - acima de $75 \%$ da superfície amarela.
Por fim, a metodologia foi calcada na análise descritiva e análise de correspondência múltipla para análise quantitativa e qualitativa dos dados.

\section{RESULTADOS E DISCUSSÃO}

\section{Perfil do mercado varejista (supermercados e varejões):}

Os principais encarregados pela negociação e aquisição do mamão nos supermercados são os encarregados da seção FLV (frutaslegumes-verduras), enquanto, nos varejões, são os próprios proprietários (Tabela 1).

TABELA 1- Pesquisa sobre o mercado varejista (supermercado e varejão) do Distrito Federal -DF.

Principal responsável pela compra

Fornecedor
Varejão

Proprietário:63,0\%; Gerente da loja: $29,6 \%$

Varejão

Supermercado Encarregado da FLV: $33,4 \%$

Outros: $25,9 \%$

Supermercado

Ceasa -DF: $76 \%$

Produtor $24 \%$

\begin{tabular}{|c|c|c|}
\hline Contrato com o fornecedor & Varejão & Supermercado \\
\hline & $7 \%$ & $44 \%$ \\
\hline Principais critérios observados durante a compra do mamão & Varejão & Supermercado \\
\hline Presença de danos físicos & $91 \%$ & $76 \%$ \\
\hline Preço & $51 \%$ & $46 \%$ \\
\hline Grau de maturação & $40 \%$ & $33 \%$ \\
\hline \multirow{2}{*}{ Estádio preferido } & Varejão & Supermercado \\
\hline & 3 a 5 & 1 a 3 \\
\hline \multirow[t]{3}{*}{ Tipos de embalagem em que os frutos são recebidos } & Varejão & Supermercado \\
\hline & Papelão: $42,6 \%$ & Madeira: $35,1 \%$ \\
\hline & Madeira: $53,7 \%$ & Plástico: $35,1 \%$ \\
\hline \multirow[t]{2}{*}{ Quantidade média de mamão adquirida } & Varejão & Supermercado \\
\hline & & de $30 \mathrm{~kg}$ \\
\hline \multirow[t]{2}{*}{ Armazenamento do mamão em depósito } & Varejão & Supermercado \\
\hline & $26 \%$ & $74 \%$ \\
\hline \multirow[t]{2}{*}{ Freqüência com que, em média, o mamão é reposto } & Varejão & Supermercado \\
\hline & 1 a 2 vezes ao dia & 3 vezes ao dia \\
\hline \multirow[t]{2}{*}{ Principal responsável pela reposição dos frutos } & Varejão & Supermercado \\
\hline & \multicolumn{2}{|c|}{ Estabelecimento (100\%) } \\
\hline Tempo médio de permanência do fruto na prateleira (dias) & Varejão & Supermercado \\
\hline 1 dia & $44 \%$ & $26 \%$ \\
\hline 2 dias & $27 \%$ & $37 \%$ \\
\hline Mais de 2 dias & $29 \%$ & $37 \%$ \\
\hline \multirow[t]{2}{*}{ Acompanhamento das perdas de mamão } & Varejão & Supermercado \\
\hline & $60 \%$ & $90 \%$ \\
\hline Perda média semanal & Varejão & Supermercado \\
\hline Perdas menores que $3 \%$ & $31 \%$ & $43 \%$ \\
\hline Perdas entre 3 a $5 \%$ & $26 \%$ & $26 \%$ \\
\hline Perdas de 5 a $10 \%$ & $43 \%$ & $31 \%$ \\
\hline Responsável pelo prejuízo das perdas & Varejão & Supermercado \\
\hline Fornecedor & $15 \%$ & $30 \%$ \\
\hline Estabelecimento & $85 \%$ & $70 \%$ \\
\hline
\end{tabular}

A Ceasa-DF é a principal fornecedora de mamão para o mercado varejista, porém observou-se que $24 \%$ dos supermercados entrevistados adquirem os frutos diretamente do produtor.

Tanto nos supermercados como nos varejões, os principais meios de transporte utilizados na entrega do mamão 'Solo' e 'Formosa', do fornecedor até o estabelecimento, são caminhões abertos e baú. Pela menor infraestrutura dos varejões situados fora do Plano Piloto, pôde-se observar a presença de utilitários (Kombi, camionete, etc) no transporte.

Nos supermercados, é comum a utilização de caixas plásticas ou de madeira no transporte dos frutos. Nos varejões, são utilizadas caixas de madeira e de papelão. Nenhum dos estabelecimentos analisados recebe o fruto sem algum tipo de embalagem - a granel.

Observou-se que, em $44 \%$ dos supermercados, havia contrato com os fornecedores. A maioria dos varejões (93\%) não possuía contrato com os fornecedores.

A presença de danos físicos é o critério mais observado na compra dos frutos pelos respectivos responsáveis dos supermercados e varejões, fator esse que aumenta a importância de utilizar-se transporte e embalagens adequados.

A quantidade média semanal de mamões adquirida pelos estabelecimentos, independentemente do grupo de mamão, foi menos de $300 \mathrm{~kg}$ na maioria dos estabelecimentos pesquisados. Devido à grande estrutura dos supermercados, a quantidade adquirida pode triplicar nos dias de promoções, podendo ultrapassar $300 \mathrm{~kg}$. Observou-se que, em dias de promoções dos supermercados, os varejões reduziam a quantidade adquirida.

Com maior espaço físico que os varejões, $74 \%$ dos supermerca- 
dos apresentam depósitos para o armazenamento dos frutos. Na maioria dos varejões, os frutos adquiridos são colocados diretamente na prateleira de comercialização sem passar por qualquer tipo de depósito. Os poucos varejões que possuem depósito, encontram-se na região Brasília.

Como há um intenso fluxo de consumidores, alta comercialização de frutos e existência de depósitos, é bastante evidente que a reposição dos frutos, na maioria dos supermercados, seja feita, em média, 3 vezes ao dia. Já nos varejões, em sua maioria, a reposição dos frutos nas prateleiras é realizada uma ou duas vezes ao dia, pois apresentam um menor fluxo de consumidores e, em sua maioria, não apresentam depósitos. O tempo de permanência dos frutos nos supermercados é superior a 1 dia. Nos varejões, devido ao alto grau de maturação dos frutos adquiridos, o tempo de permanência no estabelecimento é de 1 dia.

Os frutos ficam expostos, independentemente do tipo de mercado varejista, em prateleira sem refrigeração, conforme informações obtidas por Fagundes e Yamanishi (2002). A manutenção de temperaturas baixas na fase de exposição no mercado varejista nem sempre é possível, mas, durante o armazenamento e distribuição, os frutos devem ser acondicionados em ambientes com temperaturas adequadas. Isso, no entanto, não elimina a importância de resfriar-se os frutos nas prateleiras dos supermercados e varejões (Chitarra, 1999). Vale consignar que alguns frutos apresentam preço unitário baixo que não cobre o custo de armazenamento refrigerado (Vilas Boas, 2000). Porém, vale ressaltar a importância de realizar-se futuros estudos para avaliar a relação entre os custos de refrigeração do mamão no transporte, armazenamento e comercialização, e a redução das perdas com uso de refrigeração.

Em relação às perdas de frutos, existe um maior acompanhamento nos supermercados do que nos varejões. Em média, 90\% dos supermercados e $60 \%$ dos varejões possuem um acompanhamento das perdas.

Em $69 \%$ dos varejões, verificou-se que a perda média semanal de mamão 'Solo' foi em torno de 3\% a 10\%. O maior volume de perda dos varejões provavelmente esteja relacionado ao alto grau de maturação dos frutos adquiridos por esses estabelecimentos, uma vez que os frutos em estádios mais avançados são mais suscetíveis a injúrias causadas por choques mecânicos nas embalagens durante o transporte e no manuseio dos consumidores.

Os supermercados preferem comprar frutos em estádio de maturação menos avançado (estádios de 1 a 3), pois, segundo os responsá- veis, o tempo de prateleira é maior, e o fruto pode amadurecer e chegar em boas condições na casa do consumidor, reduzindo as perdas que, em $69 \%$ dos supermercados, foi menor que 5\%. A principal causa das perdas nos supermercados foi o excesso de frutos na bancada e o excesso de manuseio do consumidor. Essas perdas em $69 \%$ dos supermercados ficou abaixo de $5 \%$

Os varejões, por comprarem frutos nos estádios 3 e 4, atendem aos consumidores do mamão 'Solo' que, em sua maioria, preferem consumi-lo no mesmo dia da aquisição, enquanto os supermercados, por adquirirem frutos nos estádios 1 a 3, atendem aos consumidores do mamão 'Formosa', que preferem esperar seu amadurecimento em casa.

Verificou-se que grande parte das perdas ocorridas nos estabelecimentos pesquisados foi atribuída à forma de exposição dos frutos, correspondendo a 77,7\% dos estabelecimentos varejista, seguido do transporte do fornecedor até o varejo (18,5\%) e estocagem no mercado varejista $(3,8 \%)$. Essa elevada perda na exposição é conseqüência de prateleiras inadequadas e da falta de frutos de qualidade que podem estar correlacionadas às atividades desenvolvidas na pré-colheita (ex.: adubação) ou na póscolheita (ex.: transporte, embalagem e manuseio na propriedade rural), que induz o consumidor a manusear maior quantidade de frutos para escolher o que lhe agrade.

Uma forma de auxiliar a escolha do cliente é a exposição dos frutos para a degustação, pois o fruto, mesmo apresentando alguma injúria, pode estar saboroso, enquanto a boa aparência externa não é garantia de que o fruto seja saboroso. Segundo o Ministério da Integração Nacional (2001), os frutos lesionados não devem ser colocados nas gôndolas, pois provocam grande rejeição.

O ônus das perdas nos supermercados ficou, principalmente, a cargo do próprio estabelecimento, porém, em $33 \%$ dos supermercados analisados, o fornecedor arcava com as perdas. Essa responsabilidade dos fornecedores em arcar com o prejuízo foi, em grande parte, possível devido a contratos escritos ou verbais entre os fornecedores e os estabelecimentos. O prejuízo com as perdas foi absorvido pelo próprio varejão.

\section{Perfil dos consumidores de mamão do Distrito Federal:}

As Tabelas 2 e 3 tratam da apresentação do mercado consumidor do DF bem como da pesquisa sobre os consumidores exclusivos do mamão 'Solo' e 'Formosa', respectivamente.

TABELA 2- Pesquisa sobre o mercado consumidor do Distrito Federal -DF.

\begin{tabular}{|c|c|c|c|}
\hline Principal freqüência na compra do mamão & \multicolumn{3}{|c|}{$\begin{array}{l}1 \text { vez por semana: } 33,9 \% \text {; Raramente: } 17,9 \% \text {; Quinzenalmente: } 14,2 \% ; 2 \\
\text { vezes por semana: } 10,5 \% \text {; Diariamente: } 8 \% \text {; Outros: } 15.5 \%\end{array}$} \\
\hline Principal horário & \multicolumn{3}{|c|}{ Manhã: $67,3 \%$; Tarde: $14,8 \%$; Noite: $5,5 \%$; Nos três períodos: $12,4 \%$} \\
\hline Dia da semana & \multicolumn{3}{|c|}{ Não tem dia certo: $58,6 \%$; Sábado: $13,6 \%$; Quarta: 9,3\%; Outros: $18,8 \%$} \\
\hline Minutos gastos na escolha do mamão & \multicolumn{3}{|c|}{ Menos de 5: $81,4 \% ; 5$ a $10: 14,2 \%$; Outros: $4,4 \%$} \\
\hline Melhor estabelecimento para a compra do mamão: & \multicolumn{3}{|c|}{$\begin{array}{l}\text { Sacolão: } 42,6 \% \text {; Supermercado: } 41,3 \% \text {; Feira: } 3,7 \% \text {; } \\
\text { Quitandas: } 1,8 \% \text {; Outros: } 10,6 \%\end{array}$} \\
\hline Motivo pela preferência & \multicolumn{3}{|c|}{ Qualidade: $39,8 \%$; Preço: $28,8 \%$; Higiene: $26,4 \%$; Outros: $5 \%$} \\
\hline Principais características que interferem na escolha do mamão & \multicolumn{3}{|c|}{$\begin{array}{l}\text { Ausência de defeitos: } 34,7 \% \text {; Firmeza: } 26,2 \% \text {; Coloração: } 23,9 \% \text {; } \\
\text { Outros: } 15,2 \%\end{array}$} \\
\hline $\begin{array}{l}\text { Principais problemas observados quando é realizada a compra } \\
\text { dos frutos }\end{array}$ & \multicolumn{3}{|c|}{$\begin{array}{l}\text { Fruto com danos fisicos: } 32,1 \% \text {; Fruto com manchas: } 26,1 \% \text {; } \\
\text { Fruto estragado: } 19,4 \% \text {; Outros: } 22,4 \%\end{array}$} \\
\hline \multirow[t]{2}{*}{ Preferência no tipo de mamão } & Solo & Formosa & Ambos \\
\hline & $43 \%$ & $41 \%$ & $16 \%$ \\
\hline
\end{tabular}

TABELA 3- Pesquisa sobre os consumidores exclusivos do mamão 'Solo' e 'Formosa'.

\begin{tabular}{lcc}
\hline Razão da preferência & 'Solo' & 'Formosa' \\
\hline & $\begin{array}{c}\text { Sabor e } \\
\text { tamanho }\end{array}$ & Preço \\
\hline Principal forma de armazenamento & 'Solo' & 'Formosa' \\
\hline Estádios preferidos & Fruteira & Fruteira e geladeira \\
\hline & 'Solo' & 'Formosa' \\
\hline & 4 e 5 & 1 e 3 \\
\hline
\end{tabular}

Destas tabelas, depreende-se:

a) A procura pelo mamão nas regiões-satélite - Planaltina, Samambaia, Brazlândia, entre outras, é considerada pequena. A procura por outras frutas mais populares e com preços mais acessíveis, como a banana, também contribui para a redução do consumo de mamão nessas localidades. A freqüência na compra de mamão nessas regiões é uma vez por semana, quinzenalmente ou muito rara. Na região de Brasília+, onde a renda dos consumidores, em média, é superior à das demais regiões, a procura pelo mamão é maior, e a freqüência da compra, em geral, é diária 
ou 2 vezes por semana.

b) No geral, a qualidade e o preço foram os atributos mais observados pelos consumidores na escolha do estabelecimento para aquisição dos frutos.

c) Os consumidores gastam, em média, menos de 5 minutos na escolha do mamão. Mas, observou-se que esse tempo pode ser superior aos 5 minutos. Segundo $28 \%$ dos consumidores, isso era conseqüência de frutos inadequados nas gôndolas dos mercados varejistas.

d) O sabor é o principal atributo na escolha do mamão 'Solo' em detrimento do mamão 'Formosa'. Outro fator que influencia a escolha é o tamanho, pois o mamão 'Solo' pode ser consumido em um dia, e seu armazenamento é feito em fruteiras, já o mamão 'Formosa' é consumido em mais de um dia, necessitando seu armazenamento em geladeira. Esses fatores foram observados, também, pelo Ministério da Integração Nacional (2001).

e) O grau de maturação preferido pelos consumidores do mamão 'Solo' são os estádios 4 e 5 , ou seja, quando o mamão já está maduro para ser consumido imediatamente. Conforme sugerido por Souza et al. (1998), os frutos que apresentaram melhores atributos sensoriais estavam no estádio 3 .

f) O preço de venda do mamão 'Formosa' é determinante para que a procura por esse mamão seja maior do que pelo mamão ‘Solo' nas cidades-satélite. O mamão 'Formosa' é comprado quando está nos estádios de 1 a 3 , e os consumidores aguardam o seu amadurecimento para o consumo em sua residência.

g) As principais características que determinam a escolha dos frutos, são a ausência de defeitos, firmeza e coloração, características, também, observadas pelo Ministério da Integração Nacional (2001).

h) Apesar de a embalagem adequada proteger os frutos de danos físicos e de outras injúrias, $52 \%$ dos entrevistados não pagariam mais por um fruto embalado. Isso é reflexo da desconfiança do consumidor ao adquirir um produto embalado na propriedade rural, enquanto, a granel, o consumidor tem a possibilidade de escolher.

i) Os principais problemas observados pelos consumidores no momento da compra do mamão são frutos com danos físicos e frutos com manchas. Isso mostra a importância de manter a qualidade dos frutos para que esses cheguem aos consumidores com boa aparência. Segundo Vilas Boas (2000), existem muitos fatores que afetam a manutenção da qualidade e a incidência de perdas na pós-colheita. Entre elas, destacam-se: a qualidade inicial dos frutos; a temperatura e umidade em que o fruto é mantido durante o armazenamento; transporte e comercialização; tipo de embalagem utilizada na comercialização; forma de exposição dos frutos no mercado varejista.

\section{CONCLUSÕES}

1) Os resultados e discussões devem ser vistos com cautela em função do tamanho da análise e do número de clientes entrevistados. Porém, oferecem boas condições e características dos mercados varejistas e consumidor de mamão dos grupos 'Solo' e 'Formosa' no DF.

2) Devido à infra-estrutura, maior poder de barganha e maior capacidade instalada, os supermercados realizam contratos com os fornecedores que arcam com o ônus das perdas, ficando na obrigação de entregar frutos de qualidade superior. Essa infra-estrutura, por meio de depósitos, possibilita os supermercados de repor, gradativamente, os frutos nas gôndolas. Por essa razão, os supermercados preferem adquirir frutos em estádio menos avançado, apesar de os consumidores de mamão 'Solo' preferirem estádios mais avançados de maturação, quando comparados com os varejões que, por não possuírem, em sua maioria, depósitos, adquirem frutos para a comercialização imediata.

3) Outra vantagem da infra-estrutura dos supermercados é um maior acompanhamento das perdas dentro do estabelecimento, o que possibilita tomar decisões mais precisas para reduzi-las. Falta, porém, nos estabelecimentos, um programa de marketing a respeito das qualidades nutricionais dos frutos, as formas em que se pode consumi-los e determinar a melhor maneira de armazená-los.

4) A maioria dos consumidores de mamão 'Formosa' preferemno devido ao menor preço, se comparado ao do mamão 'Solo'. Por isso, ao reduzir-se as perdas, podem-se diminuir os custos e o preço para o consumidor final, aumentando, assim, o consumo de mamão dos grupos 'Solo' e 'Formosa'.

\section{REFERÊNCIAS BIBLIOGÁFICAS}

AMARO, A. A. Cadeia produtiva de frutas. São Paulo, SP: Secretaria de abastecimento do Estado de São Paulo, 1997.

AMARO, A. A. Mercado interno de frutas. In: CONGRESSO BRASILEIRO DE FRUTICULTURA 1998, Poços de Caldas MG. Conferência... p.168-172.

CHITARRA, A. B. Armazenamento de frutos e hortaliças por refrigeração. Lavras (MG): UFLA/FAEPE,1999. 60p.

MINISTÉRIO DA INTEGRAÇÃO NACIONAL, Estudo qualitativo sobre as frutas. Brasília, DF: 2001.p 20-27, 54.

FAGUNDES, G. R.; YAMANISHI, O, K. Estudo da comercialização do mamão em Brasília - DF. Revista Brasileira de Fruticultura, Jaboticabal, v. 27, n. 1, p. 91-95, 2002.

GONÇALVES, J. O século do consumidor. Revista da Associação Brasileira de Supermercados - SuperHiper. São Paulo, v. 27, n. 307, p. 8 $18,2001$.

PERFIL dos estabelecimentos e caracterização do mercado consumidor de frutas e hortaliças no setor supermercadista do estado de Goiás e do Distrito Federal. Brasília, DF: Intelecto/Consultoria, Estudo \& Projetos, 1998.

SILVA, E.M.F da. Estudos sobre mercado de frutas. São Paulo: FIPE, 1999.373p.

SOUZA, G de; VIANNI, R.; MARIN, S. L. D.; OLIVEIRA, M. A. Avaliação sensorial do fruto de cinco cultivares de mamoeiro (Carica papaya L.) produzidas em Macaé-RJ. In: CONGRESSO BRASILEIRO DE FRUTICULTURA 1998, Poços de Caldas MG. ...Resumos p.505.

VILAS BOAS, E. V. B. Perdas pós-colheita. Lavras (MG): UFLA/FAEPE, 2000,60p 